\title{
Fabrication and Application of Novel Porous Scaffold in Situ-Loaded Graphene Oxide and Osteogenic Peptide by Cryogenic 3D Printing for Repairing Critical-Sized Bone Defect
}

\author{
Yidi Zhang ${ }^{1,2}$, Chong Wang ${ }^{3, *}$, Li Fu ${ }^{1,2}$, Shan Ye ${ }^{1,2}$, Min Wang ${ }^{4}$ and Yanmin Zhou ${ }^{1,2, *}$ \\ 1 Department of Oral Implantology, School of Stomatology, Jilin University, Changchun 130021, China; \\ ydzhang16@mails.jlu.edu.cn (Y.Z.); fuli1127@126.com (L.F.); yeshan16@mails.jlu.edu.cn (S.Y.) \\ 2 Jilin Provincial Key Laboratory of Tooth Development and Bone Remodeling, Changchun 130021, China \\ 3 College of Mechanical Engineering, Dongguan University of Technology, Songshan Lake, Dongguan 511700, \\ Guangdong, China \\ 4 Department of Mechanical Engineering, The University of Hong Kong, Pokfulam Road, Hong Kong 999077, \\ China; memwang@hku.hk \\ * Correspondence: wangchong@dgut.edu.cn (C.W.); zhouym@jlu.edu.cn (Y.Z.); \\ Tel.: +86-134-1688-5162 (C.W.); +86-0431-8879-6025 (Y.Z.)
}

Received: 12 March 2019; Accepted: 26 April 2019; Published: 28 April 2019

check for updates

\begin{abstract}
Osteogenic peptides have been reported as highly effective in directing mesenchymal stem cell osteogenic differentiation in vitro and bone formation in vivo. Therefore, developing novel biomaterials for the controlled delivery of osteogenic peptides in scaffolds without lowering the peptide's biological activity is highly desirable. To repair a critical-sized bone defect to efficiently achieve personalized bone regeneration, a novel bioactive poly(lactic-co-glycolic acid) (PLGA)/ $\beta$-tricalcium phosphate ( $\beta$-TCP) composite scaffold, in which graphene oxide $(\mathrm{GO})$ and bone morphogenetic protein (BMP)-2-like peptide were loaded in situ (PTG/P), was produced by an original cryogenic 3D printing method. The scaffolds were mechanically comparable to human cancellous bone and hierarchically porous. The incorporation of GO further improved the scaffold wettability and mechanical strength. The in situ loaded peptides retained a high level of biological activity for an extended time, and the loading of GO in the scaffold further tuned the peptide release so that it was more sustained. Our in vitro study showed that the PTG/P scaffold promoted rat bone marrow-derived mesenchymal stem cell ingrowth into the scaffold and enhanced osteogenic differentiation. Moreover, the in vivo study indicated that the novel PTG/P scaffold with sustained delivery of the peptide could significantly promote bone regeneration in a critical bone defect. Thus, the novel bioactive PTG/P scaffold with a customized shape, improved mechanical strength, sustainable peptide delivery, and excellent osteogenic ability has great potential in bone tissue regeneration.
\end{abstract}

Keywords: osteogenic peptide; sustained delivery; bone tissue engineering; scaffolds; graphene oxide

\section{Introduction}

To date, safely and effectively regenerating bone tissues in a critical-sized defect remains a great challenge; hence, guided bone regeneration (GBR) is required [1,2]. Scaffolds play a critical role in GBR because they provide structural supports, influence cell behaviors, and serve as templates in the process of bone healing [3]. Autografts are the current gold standard because they trigger minimal immunogenic response during the reconstruction, but their applications are restrained by a limited donor supply and secondary trauma. Currently, a highly desirable goal is the production of scaffolds for 
bone regeneration, as scaffolds can mimic the structure of native bone tissue, release biologically active agents in a controlled way, and degrade with the formation of the new bone. Calcium phosphate-based ceramic materials are favorable for fabricating bone substitutes, as ceramic's crystal and chemical structures are extremely similar to those of the native bone [4]. However, new bone formation in bioceramic scaffolds alone is limited.

Many clinical studies have demonstrated the excellent osteoinductivity of bone morphogenetic proteins (BMPs), especially BMP-2, but the direct use of BMP-2 in bone regeneration is hindered by its high cost and short half-life [5,6]. Therefore, the BMP-2-like osteogenic peptide, a safe and cost-effective synthetic osteoinductive peptide, has been increasingly used as a potent alternative to induce osteogenesis [7,8]. Generally, the rapid release and degradation of osteoinductive drugs compromise their function. Therefore, the development of a smart delivery system that allows the drug to be released sustainably is necessary for the optimization of osteoinductive drugs [9].

Recently, graphene oxide (GO), a 2D material that is oxidized from graphene and has better solubility and more favorable chemical characteristics than graphene, has been reported to absorb growth factors, collagen, and other proteins [10,11]. Studies have shown that GO can absorb these bioactive substances because it has an ultrahigh surface area-to-volume ratio, covalent conjunction, a $\pi-\pi$ stacking structure, and excellent electrostatic interactions with biomolecules [12,13]. On the basis of these binding mechanisms, loading bioactive drugs onto the GO surface is a meaningful strategy to achieve sufficient drug concentrations for an extended time. So far, most studies have incorporated GO or GO-loaded drugs into the scaffolds via post-deposition treatment in light of their unstable properties, but this strategy has proved to be very inefficient $[14,15]$. Another disadvantage of post-deposition incorporation is that it can cause a relatively high concentration of GO in local areas. A high concentration of GO can generate strong reactive oxygen species (ROS), which are harmful to the tissue repair process [16]. Although GO can be incorporated into scaffolds using electrospinning or a template, it is difficult to achieve the high mechanical strength required for a bone substitute and to match the shape of the bone defect [17-19]. Thus, it remains challenging to establish a methodology to produce GO-incorporated scaffolds that can realize the sustained release of bioactive drugs/molecules as well as a controllable shape and microstructure, especially a mechanical strength that matches that of the native bone.

Cryogenic 3D printing is a recently developed rapid prototyping technology that can fabricate scaffolds with a predesigned shape, controllable architecture, and adequate mechanical strength at the relatively low temperature of $-32{ }^{\circ} \mathrm{C}$, allowing the incorporation of a large quantity of biomolecules/drugs in situ into scaffolds and the retention of a high level of the biomolecule's biological activity [20]. Cryogenic 3D printing avoids conventional 3D printing's disadvantages, such as UV light and the post-sintering use of a high-power laser, and it shows great potential in tissue engineering. To the best of our knowledge, the in situ incorporation of GO-loaded drugs/biomolecules into scaffolds by 3D printing has barely been explored.

In this study, we incorporated GO nanosheets adsorbed with the BMP-2-like osteogenic peptide (GO@peptide) into poly(lactic-co-glycolic acid) (PLGA)/ $\beta$-tricalcium phosphate ( $\beta$-TCP) composite scaffolds in situ through cryogenic 3D printing for the first time. Our objective is to develop a biodegradable scaffold with improved in vitro osteogenic differentiation capability and enhanced in vivo bone forming ability while avoiding the technical, clinical, and manufacturing limitations of existing 3D-printed bone tissue engineering scaffolds. Our scaffolds, produced through cryogenic 3D printing, were hierarchically porous and mechanically comparable to human cancellous bone. The in situ loading of GO@peptide into scaffolds achieved the sustained release of the peptide, which retained a high level of its biological activity. The proliferation and in vitro osteogenic differentiation of rat mesenchymal stem cells (rMSCs) were also significantly improved by our scaffolds, which also significantly improved the in vivo bone regeneration of cranial defects in rats. 


\section{Materials and Methods}

\subsection{Materials}

The BMP-2-like peptide (sequence from N to C: KIPKA SSVPT ELSAI STLYL SGGC) was synthesized by Shanghai ZiYu Biotech Co. (Shanghai, China). GO and $\beta$-TCP were purchased from Sigma-Aldrich (St. Louis, MO, USA), and dichloromethane (DCM) was purchased from Aladdin Tech, China. PLGA (LA/GA = 50/50, Mw = 100,000) was obtained from Jinan Daigang Biomaterial Co., Ltd., Jinan, China. Dulbecco's Modified Eagle Medium (DMEM)/F12 and fetal bovine serum (FBS) were purchased from Gibco, Grand Island, NY, USA. Penicillin-streptomycin and trypsin were obtained from Hyclone (Los Angeles, CA, USA).

\subsection{Formulation of Water/Oil Composite Emulsion Inks and Cryogenic 3D Printing of Scaffolds}

Briefly, $60 \mathrm{mg}$ of GO nanosheets was added to $10 \mathrm{~mL}$ of distilled water by ultrasonication for $4 \mathrm{~h}$ to obtain a uniform GO/water suspension. Then, $10 \mathrm{mg}$ of the BMP-2-like peptide was dissolved in $300 \mu \mathrm{L}$ of deionized water to form a peptide/water solution. The BMP-2-like peptide solution was mixed with $1 \mathrm{~mL}$ of GO solution and stirred at room temperature for $24 \mathrm{~h}$ to allow the absorption of the BMP-2-like peptide onto GO nanosheets. After that, $150 \mu \mathrm{L}$ of collagen I (COL-I) solution with a concentration of $9.73 \mathrm{mg} / \mathrm{mL}$ (Corning, USA) and $3.45 \mu \mathrm{L}$ of $\mathrm{NaOH}(1 \mathrm{~N})$ were added to the GO solution and further stirred for $10 \mathrm{~min}$. The GO@peptide solution was successfully produced. Subsequently, $1.5 \mathrm{~g}$ of PLGA was dissolved in $10 \mathrm{~mL}$ of DCM solution to form a homogeneous solution with a $15 \%(w / v)$ concentration. Afterward, $1 \mathrm{~mL}$ of the aforementioned GO@peptide solution and $15 \mu \mathrm{L}$ of Tween 20 were mixed with $10 \mathrm{~mL}$ of the PLGA/DCM solution by using continuous magnetic stirring to form the water/oil emulsion inks. Then, $1.5 \mathrm{~g}$ of $\beta$-TCP powder was added to the aforementioned ink and stirred with a glass rod to form a uniform liquid paste. A series of PLGA/ $\beta$-TCP/GO@peptide (PTG) compounds with varied GO concentrations (e.g., 0, 0.025, 0.05, and 0.1 wt.\% with respect to the final mixture) was produced and designated as 'PT/P', '0.025PTG/P', '0.05PTG/P', and '0.1PTG/P', respectively. The PLGA/ $\beta$-TCP scaffold without peptide was generated as the negative control and denoted as 'PT'. The paste was extruded layer by layer at $-32{ }^{\circ} \mathrm{C}$ from a programmed nozzle to form a cubic porous scaffold with the dimensions $10 \times 10 \times 5 \mathrm{~mm}$ using a cryogenic 3D printing machine (Creality 3D Technology Co., Ltd., Shenzhen, China) according to a predesigned 3D model, in which the macropore size was set to $400 \mu \mathrm{m}$, the layer thickness was $0.32 \mathrm{~mm}$, the printing speed was $15 \mathrm{~mm} / \mathrm{s}$, the extrusion speed was $0.006 \mathrm{~mm} / \mathrm{s}$, and printing was done with a needle of 22G. Afterward, lyophilization was performed for $24 \mathrm{~h}$ to remove the DCM.

\subsection{Characterization of Original Materials, GO Nanosheets and Scaffolds}

The phase of GO, $\beta$-TCP and PLGA were tested by X-ray diffraction (XRD). High-Performance Liquid Chromatography (HPLC) was used to analyze the purity of the peptides. The morphology and thickness of GO were characterized by atomic force microscopy (AFM, Bruker Dimension Icon, Billerica, MA , USA) under tapping mode. The samples were sputter-coated with $10 \mathrm{~nm}$ of gold and then observed under a cold-field emission scanning electron microscope (SEM, SU8010, Hitachi, Japan). The functional groups in the GO and PTG composite scaffolds were analyzed using a fully automated laser Raman microscope (LabRAM HR800, HORIBA Jobin Yvon, France) with a 633 nm excitation wavelength and 50× magnification at room temperature. The static contact angle of water droplets on the scaffolds ( $n=3$ for each group) was determined with an optical measuring instrument. Three different points of a droplet on each sample were measured, and images were captured with a CCD camera (VCA-2000, AST). The porosity of the scaffolds was characterized by the water immersion method. Briefly, the scaffolds were freeze-dried and weighed. Thereafter, the scaffolds were placed in 
a vacuum oven immersed in water until no bubbles appeared. The porosity $(P)$ of the scaffolds was calculated as follows:

$$
P=\frac{W_{1}-W_{2}}{W_{1}-W_{3}} \times 100 \%
$$

where $W_{1}$ is the scaffold weight after freeze-drying, $W_{2}$ is the weight of the water-saturated scaffold, and $W_{3}$ is the floating weight after the scaffold was immersed in water.

\subsection{In Vitro Peptide Release and Scaffold Degradation}

The scaffolds were sectioned into cubes with the dimensions $5 \times 5 \times 10 \mathrm{~mm}$ and then immersed in a $15 \mathrm{~mL}$ centrifuge tube containing $10 \mathrm{~mL}$ of DMEM/F12 with $1 \%$ penicillin-streptomycin at $37^{\circ} \mathrm{C}$ for up to 8 weeks in a shaking water bath at $120 \mathrm{rpm}$; this process was carried out according to the guideline titled Biological Evaluation of Medical Devices-Part 12: Sample Preparation and Reference Materials (ISO 10993-12:2012, URL: https://www.iso.org/standard/53468.html). The degradation medium was changed and collected at specific time points and then subjected to HPLC with a UV-vis detector at a wavelength of $220 \mathrm{~nm}$ for detecting the amount of peptide. The scaffolds were lyophilized and subjected to compression testing at week $0,2,4,6$, and 8 . The compression test was conducted using a universal testing machine (ELF 3200, Bose, USA) at $1 \mathrm{~mm} / \mathrm{min}$ for $5 \mathrm{~min}$ under the standard temperature condition. The weight loss of scaffolds was also examined every 2 weeks for up to 8 weeks. The weight remaining ratio was calculated as follows:

$$
\text { Weight remaining ratio }(\%)=\frac{W_{t}}{W_{0}} \times 100 \%
$$

where $W_{0}$ is the weight at week 0 and $W_{t}$ is the weight tested at different time points after degradation. At least three samples were tested for each type of scaffold, and the mean and standard deviation were calculated.

\subsection{In Vitro Biological Performance}

The rMSCs were isolated from Wistar rats according to established protocols and cultured in DMEM/F12 supplemented with $10 \%$ FBS and $1 \%$ penicillin-streptomycin at $37^{\circ} \mathrm{C}$ in a $5 \% \mathrm{CO}_{2}$ incubator. Confluent cells were detached with a mixture of $0.25 \%$ trypsin. Aliquots of separated cells were then subcultured. The third-passage cells were employed to conduct the following experiment.

\subsubsection{Cell Viability Evaluation}

The rMSCs were seeded on different scaffolds placed in a 24-well culture plate at a density of $1 \times 10^{5}$ cells/well and incubated at $37^{\circ} \mathrm{C}$ for $24 \mathrm{~h}$, allowing the cells to adhere to the scaffolds. After culturing for 1 day, the cell/scaffold constructs were shifted to a new culture plate. The cytotoxicity of the scaffolds was assessed by live/dead assay (Live/Dead Imaging Kit, Molecular Probes, Life Technologies, Waltham, MA, USA) after culturing rMSCs on them for 3 days. In brief, the working solution was prepared by mixing Calcein AM and propidium iodide to stain live and dead cells, respectively. The cells were incubated in the working solution for $15 \mathrm{~min}$ and then observed under a fluorescence microscope. The proliferation of rMSCs was detected by the Cell Counting Kit- 8 assay (CCK-8, Dojindo Laboratories, Kyushu Island, Japan) on day 1, 4, and 7. Briefly, cells were incubated with blends of CCK-8 solution and fresh medium at a ratio of 1:10 for $1 \mathrm{~h}$, and the OD value of each group was measured at $450 \mathrm{~nm}$ with a microplate reader (BioTek, Winooski, VT, USA).

\subsubsection{Cell Adhesion and Morphology}

The rMSCs were seeded on different scaffolds placed in 24-well culture plates at a density of $1 \times 10^{5}$ cells/well and incubated at $37^{\circ} \mathrm{C}$ for $24 \mathrm{~h}$, allowing the cells to adhere to the scaffolds. After culturing for 1 day, the cell/scaffold constructs were shifted to a new culture plate. Cells were fixed with $4 \%$ paraformaldehyde for $30 \mathrm{~min}$ and washed thrice with PBS. They were added to $200 \mu \mathrm{L}$ of BSA 
block solution with $1 \%(w / v)$ concentration and incubated for $1 \mathrm{~h}$. Then, they were incubated with specific primary antibodies (Anti-vinculin, [BM4051, Boster]) overnight at $4{ }^{\circ} \mathrm{C}$, and the cell/scaffold constructs were incubated in an aqueous solution of Alexa Fluor 555 Goat Anti-Rabbit $\operatorname{IgG}(\mathrm{H}+\mathrm{L})$ (Life Technologies, Waltham, MA, USA) for $1 \mathrm{~h}$. The F-actin of the fixed cells was stained with Alexa Fluor 488 Phalloidin (AAT, Sunnyvale, CA, USA) for $30 \mathrm{~min}$, and 4',6-diamidino-2-phenylindole (DAPI) was simultaneously added to stain the nuclei for $15 \mathrm{~min}$. The stained cells were observed by confocal laser scanning microscopy (CLSM, FV1000 camera, Olympus Optical, Tokyo, Japan). The densities of F-actin and vinculin were analyzed by measuring the positive F-actin area using Image J software (Bethesda, MD, USA). After culturing for 3 days, the samples were observed by SEM. Cell/scaffold constructs were fixed with $2.5 \%$ glutaraldehyde for $12 \mathrm{~h}$, dehydrated by graded ethanol, and dried at the critical point. The samples were sputter-coated with $10 \mathrm{~nm}$ of gold before observation.

\subsection{Osteogenic Differentiation}

Approximately $1 \mathrm{~g}$ of the scaffolds from each group was immersed in $10 \mathrm{~mL}$ of standard osteogenic induction medium containing DMEM/F12 supplemented with 10\% FBS, 1\% penicillin-streptomycin, $0.25 \mathrm{mM}$ ascorbic acid, $10 \mathrm{mM} \beta$-glycerophosphate, and $10 \mathrm{nM}$ dexamethasone. On day 10, the conditioned medium was collected and stored at $-20{ }^{\circ} \mathrm{C}$.

\subsubsection{ALP Activity and Cell Mineralization}

Cells were seeded in a 6-well culture plate at a density of $2 \times 10^{5}$ cells/well, containing the aforementioned conditioned medium. The alkaline phosphatase (ALP) activity of the cells was assessed using the ALP activity colorimetric assay kit (BioVison, Milpitas, CA, USA) and BCA protein kit assay (Thermo Fisher Scientific, Waltham, MA, USA) following the protocol used in our previous investigation [21]. ALP staining (Promega, Madison, WI, USA) was conducted on day 7 to confirm the results of the ALP activity assay. The mineralization of rMSCs was assessed on day 21 by Alizarin Red S (ARS) staining (Solarbio, Beijing, China). Briefly, the cells were fixed with $4 \%$ paraformaldehyde for 15 min and stained with $2 \%$ Alizarin Red S solution for 30 min at $37^{\circ} \mathrm{C}$, followed by washing with PBS twice. Then, the stained calcium nodules were observed under an optical microscope.

\subsubsection{Osteogenic Gene Expression}

Quantitative real-time polymerase chain reaction (qRT-PCR) was conducted to determine the osteogenic gene expression of rMSCs on scaffolds. Cells were seeded in a 6-well culture plate at a density of $2 \times 10^{5}$ cells/well and collected after 7 and 14 days. Total RNA was extracted using Trizol reagent (Invitrogen, Waltham, MA, USA) and then reverse-transcribed using the RevertAid kit (Takara Bio, Otsu, Japan) in accordance with the manufacturer's instructions. Gene expression was assessed using TB Green qPCR Super Mixture (Takara Bio) on the ABI 7300 instrument (ABI, Foster City, Foster City, CA, USA). ALP, Runt-related Transcription Factor 2 (RUNX-2), osteocalcin (OCN), osteopontin (OPN), and COL-I were chosen as target genes for analysis, and glyceraldehyde-3-phosphate dehydrogenase (GADPH) was used as an endogenous housekeeping gene. The sequences of the primers for these genes are given in Table 1 (Invitrogen, USA). The qPCR conditions were as follows: $95^{\circ} \mathrm{C}$ for $30 \mathrm{~s}$, followed by $95^{\circ} \mathrm{C}$ for $5 \mathrm{~s}$ and $60^{\circ} \mathrm{C}$ for $31 \mathrm{~s}$ for 40 cycles. The relative mRNA expression of ALP, RUNX-2, OCN, OPN, and COL-I was normalized to that of the housekeeping gene. 
Table 1. Forward (F) and reverse (R) primers for target genes.

\begin{tabular}{ccc}
\hline Primer & Sequence $\left(\mathbf{5}^{\prime} \mathbf{- 3}^{\prime}\right)$ (Forward) & Sequence $\left(\mathbf{5}^{\prime} \mathbf{-} \mathbf{3}^{\prime} \mathbf{)}\right.$ ( Reverse $^{\prime}$ \\
\hline GADPH & ACCACAGTCCATGCCATCAC & TCCACCACCCTGTTGCTGTA \\
ALP & GTCCCACAAGAGCCCACAAT & CAACGGCAGAGCCAGGAAT \\
RUNX-2 & CCACCTCTGACTTCTGCCTC & TATGGAGTGCTGCTGGTCTG \\
OCN & GGGCAATAAGGTAGTGAA & GTAGATGCGTTTGTAGGC \\
OPN & AGCTGGATGACCAGAGTGCT & TGAAATTCATGGCTGTGGAA \\
COL-I & CCTGGAAGAGATGGTGCT & CATTCTTGCCAGCAGGAC \\
\hline
\end{tabular}

\subsection{In Vivo Animal Test}

The experimental protocol was formally approved by the Animal Care and Experiment Committee of the Animal Center of Norman Bethune Health Science Center attached to Jilin University (ethics approval number is (2018) No. 53). The in vivo study was pegrformed on 24 male Wistar rats (6 weeks old, body weight: $220-250 \mathrm{~g}$ ). The rats were randomly divided into 4 groups: the control group rats were left without scaffolds, and the PT, PT/P, and PTG/P groups correspond to rats with scaffolds of differing compositions $(n=6)$. Briefly, the rats were anesthetized by intraperitoneal injection of chloral hydrate $(10 \%)$, and then calvarial defects were made using a trephine drill with a diameter of $5 \mathrm{~mm}$ on each side of the midline in each animal. The scaffolds, with a diameter of $5 \mathrm{~mm}$ and thickness of $1 \mathrm{~mm}$, were implanted in both sides of the animals; then, the soft tissue was carefully sutured. In the control group, the defects were left without scaffolds. Each rat received an intraperitoneal injection of antibiotics for 3 days post-surgery.

\subsubsection{Polyfluorochrome Sequential Labeling}

Sequential fluorescence labeling was used to evaluate the speed of bone formation. After implantation for 2 weeks and 4 weeks, the rats received alizarin red S ( $20 \mathrm{mg} / \mathrm{kg})$ and calcein green $(20 \mathrm{mg} / \mathrm{kg})$, respectively.

\subsubsection{Micro-CT Evaluation and Histological Evaluation}

At 4 weeks and 12 weeks post-surgery, the animals were sacrificed; the skulls were removed, together with the bone defect sites, and kept in $10 \%$ formaldehyde solution at $4{ }^{\circ} \mathrm{C}$ for 10 days. The skulls were scanned using micro-CT ( $\mu$-CT50, Scanco, Swiss). Then, the specimens were dehydrated in a graded series of ethanol and soaked in methylmethacrylate polymer. The specimens were cut using Exact Cutting and Grinding Equipment (EXAKT310CP, Oklahoma City, Germany) at the center of the defect with a thickness of $60 \mu \mathrm{m}$. Fluorescent labeling was observed under a fluorescence microscope. Then, the sections were stained with toluidine blue staining and methylene blue acid fuchsin staining. Then, the sections were observed under a light microscope (Olympus U-RFL-T, Tokyo, Japan) and analyzed with Image-Pro Plus. In addition, 4 weeks after surgery, the major organs (heart, liver, spleen, and kidney) were collected and fixed with $10 \%$ formaldehyde for $24 \mathrm{~h}$. The samples were then dehydrated and embedded in paraffin. The hematoxylin and eosin stain was used to visualize the specimens.

\subsection{Statistical Analysis}

All of the experiments were conducted in quadruplicate. One-way ANOVA followed by the Least Significant Difference (LSD) test and Student-Newman-Keuls (SNK) test were performed to determine the statistical differences using IBM SPSS 23.0. For all analyses, $p<0.05\left({ }^{*}\right)$ indicates statistically significant differences. 


\section{Results}

\subsection{Design of PTG/P Scaffolds}

Figure 1 shows the schematic of the production and function of the PTG/P scaffolds. The peptide and COL-I were first adsorbed onto the GO nanosheets and then loaded into PLGA/ $\beta$-TCP/DCM solutions to form the composite emulsions used as printing inks. The collagen solution and the DI water added to the mixture protected the biological activity of the peptides from the organic solution. Afterward, PTG/P scaffolds with a designed shape and macroscopic architecture could be built via cryogenic 3D printing. Our design allows for a high loading level of the peptide. The in vitro rMSC osteogenic differentiation and in vivo bone regeneration were achieved via the controlled delivery of the peptide and the unique morphology of the scaffolds. In addition, the functional groups in GO can interact with the amino groups in the peptide, and the interaction also helps control the release rate of peptides. This design is highly favorable for the proliferation and osteogenic differentiation of rMSCs.

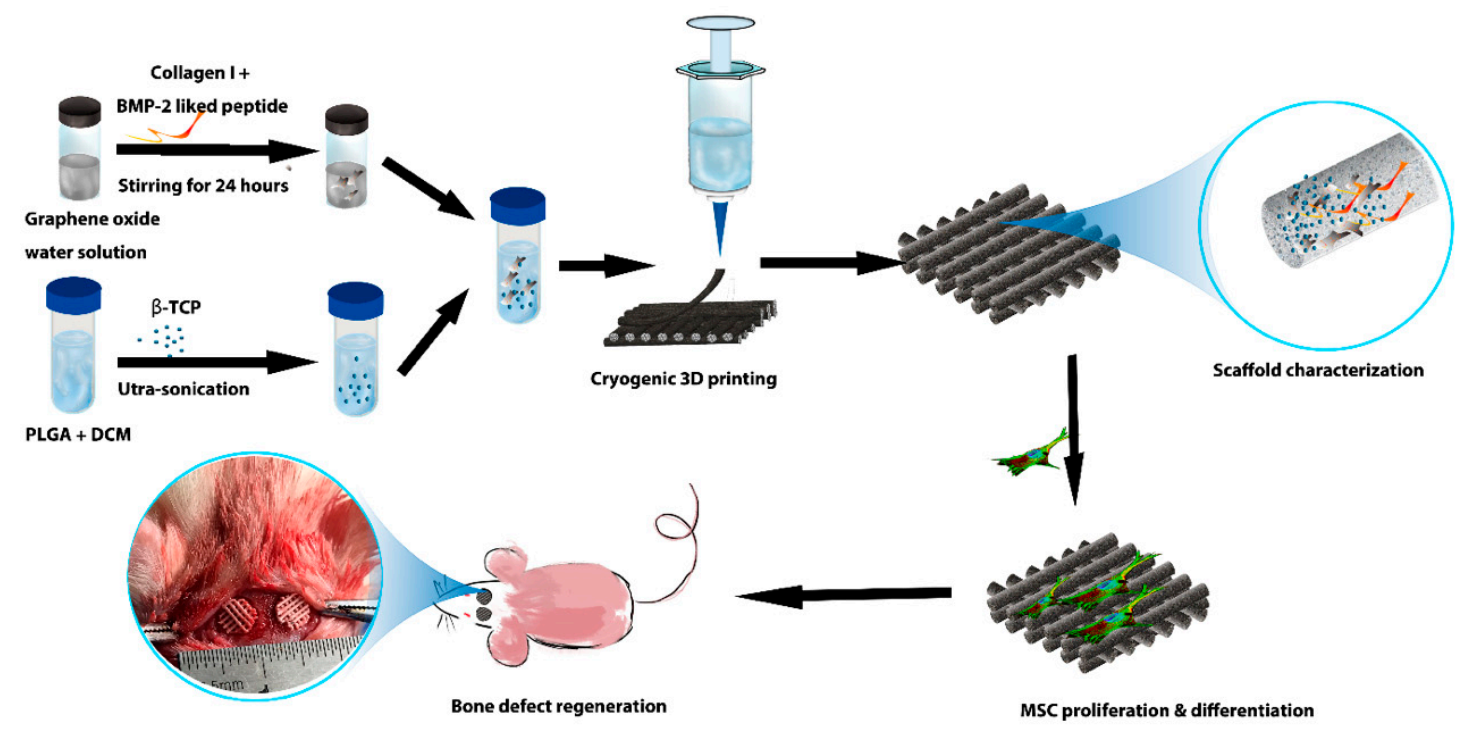

Figure 1. Schematic for the fabrication and function of peptide/GO/ $\beta-T C P / P L G A$ scaffolds.

\subsection{Characterization of Scaffolds}

The XRD spectrum and HPLC results of peptide are shown in Figure S1. The AFM images of GO nanosheets suggest that GO nanosheets with an average height of $0.5-1 \mathrm{~nm}$ had a single-layer structure (Figure 2a,b). The morphology of GO nanosheets, as detected by SEM, is shown in Figure 2c. The cryogenic 3D-printed scaffolds had a well-designed latticed structure with the dimensions $15 \times 15 \times 5 \mathrm{~mm}$ (Figure 2d). Uniform square macropores with an average pore size of $400 \pm 50 \mu \mathrm{m}$ were observed in all scaffolds, and no statistical difference was found among these groups (Figure 2e). Numerous micropores with a 5-50 $\mu$ m diameter were observed on the strut surface. This could be attributed to the ice particles formed in the frozen PLGA/ $\beta$-TCP pattern, which maintained the space until freeze-drying. The colors of these scaffolds changed from white to black with the increase of GO content, which could be attributed to the influence of the natural color of GO. Figure S2 shows the Raman spectrum mapping of the D band density of PTG scaffold, indicating that the GO is uniformly distributed on the surface of PTG/P scaffold. Figure S3 shows that the GO nanosheet without peptide showed a smooth morphology (Figure S3a). After adding the peptide, the morphology became rippled with homogeneous wrinkles (Figure S3b). 

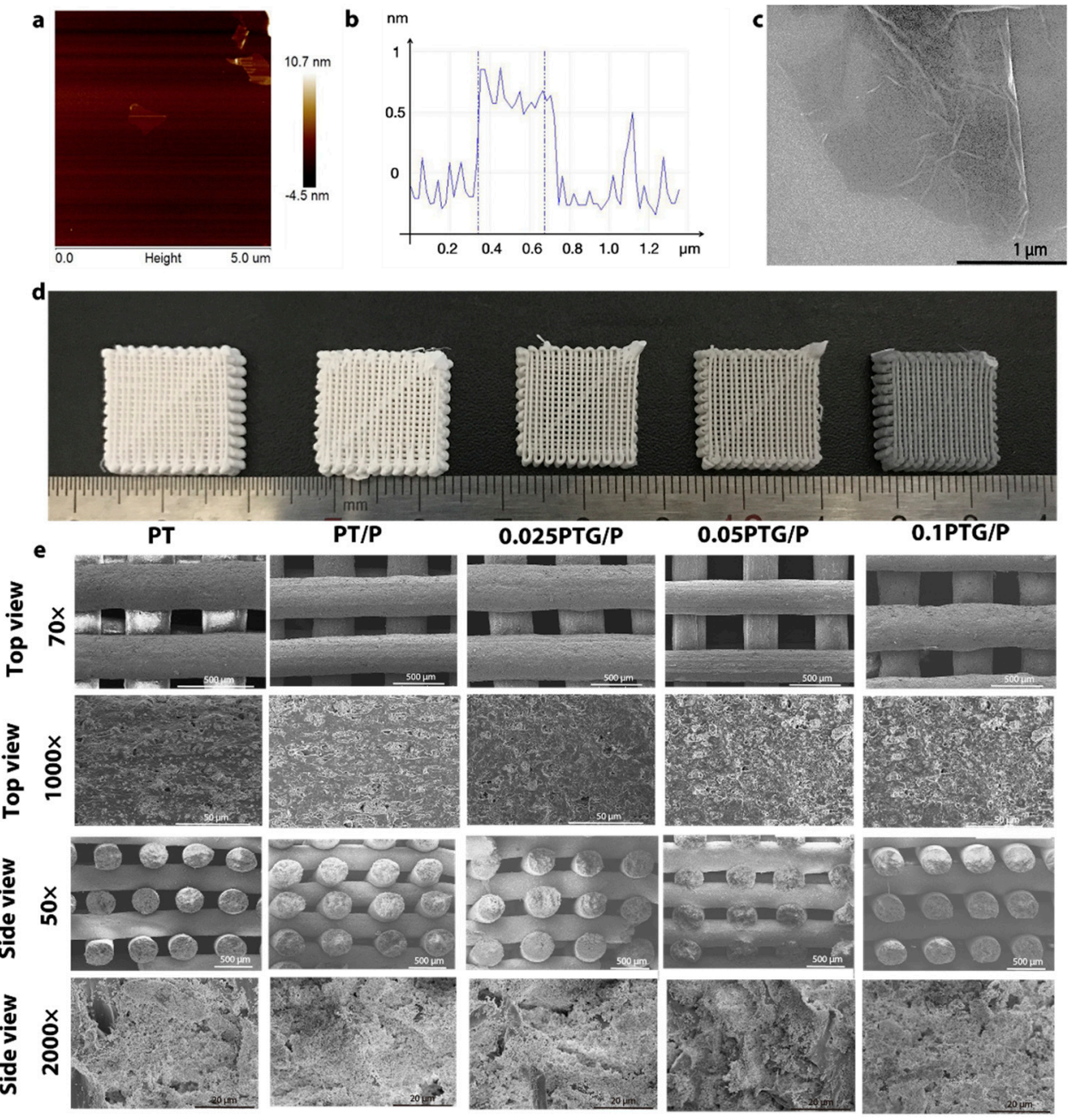

Figure 2. Characterization of the scaffolds: (a) AFM topography images of GO; (b) Analysis of the height profiles of GO; (c) SEM images of GO; (d) Images of PT, PT/P, 0,025PTG/P, 0.05PTG/P, and 0.1PTG/P (from left to right); (e) SEM and high-resolution SEM images of PT, PT/P, 0,025PTG/P, 0.05PTG/P, and $0.1 \mathrm{PTG} / \mathrm{P}$.

The Raman spectrum shows how the GO nanosheets interacted with the PT scaffolds. The spectrum of GO shows two characteristic peaks of the D and $G$ bands at 1336 and $1606 \mathrm{~cm}^{-1}$, respectively (Figure 3a). In the spectrum of PT scaffolds, peaks at $2946 \mathrm{~cm}^{-1}$ were attributed to the stretching vibration of $\mathrm{C}-\mathrm{H}$. Peaks at $970 \mathrm{~cm}^{-1}$ were due to the stretching vibration of $\mathrm{C}-\mathrm{C}$. No prominent bands within 1300-1600 $\mathrm{cm}^{-1}$ were observed in the PT scaffold (Figure $3 \mathrm{~b}$ ). In the spectra of the 0.025PTG/P, 0.05PTG/P, and 0.1PTG/P scaffolds, the D and G band peaks were observed, indicating the successful hybridization of GO and the PT/P scaffold. Figure $3 \mathrm{c}$ shows the FTIR-ATR spectra of PLGA, $\beta$-TCP, PT/P, 0.025PTG/P, 0.05PTG/P, and 0.1PTG/P scaffolds. For $\beta$-TCP, the peaks at $1001 \mathrm{~cm}^{-1}$ could be the $\mathrm{PO}_{4}{ }^{3-}$ group in $\beta-\mathrm{TCP}$, and the peaks at around $540 \mathrm{~cm}^{-1}$ could be $\mathrm{Ca}$ and $\mathrm{P}$ particles in $\beta$-TCP. For PLGA, the peaks at $2949 \mathrm{~cm}^{-1}$ could be the stretching vibrations of $\mathrm{C}-\mathrm{H}$, and the peaks at 1452,1422 , and $1383 \mathrm{~cm}^{-1}$ could be the bending vibration of $\mathrm{C}-\mathrm{H}$. The peaks at 1744 and $1082 \mathrm{~cm}^{-1}$ could be the stretching vibration of $\mathrm{C}=\mathrm{O}$ and $\mathrm{C}-\mathrm{O}$, respectively. The spectra of PT/P, 0.025PTG/P, 0.05PTG/P, and 0.1PTG/P show both of these peaks, indicating successful integration. Figure $3 \mathrm{~d}$ shows the water contact angles (WCAs) of different scaffolds. PT scaffolds had a relatively high average WCA of $81.75 \pm 7.13^{\circ}$. However, for the PTG/P groups, the average WCA decreased from $53.7 \pm 0.26^{\circ}$ to $35.48 \pm 3.84^{\circ}$ with increasing GO content. The porosity of the scaffolds was approximately $75 \%$, and no statistical difference was found among the different groups (Figure 3e). 
a
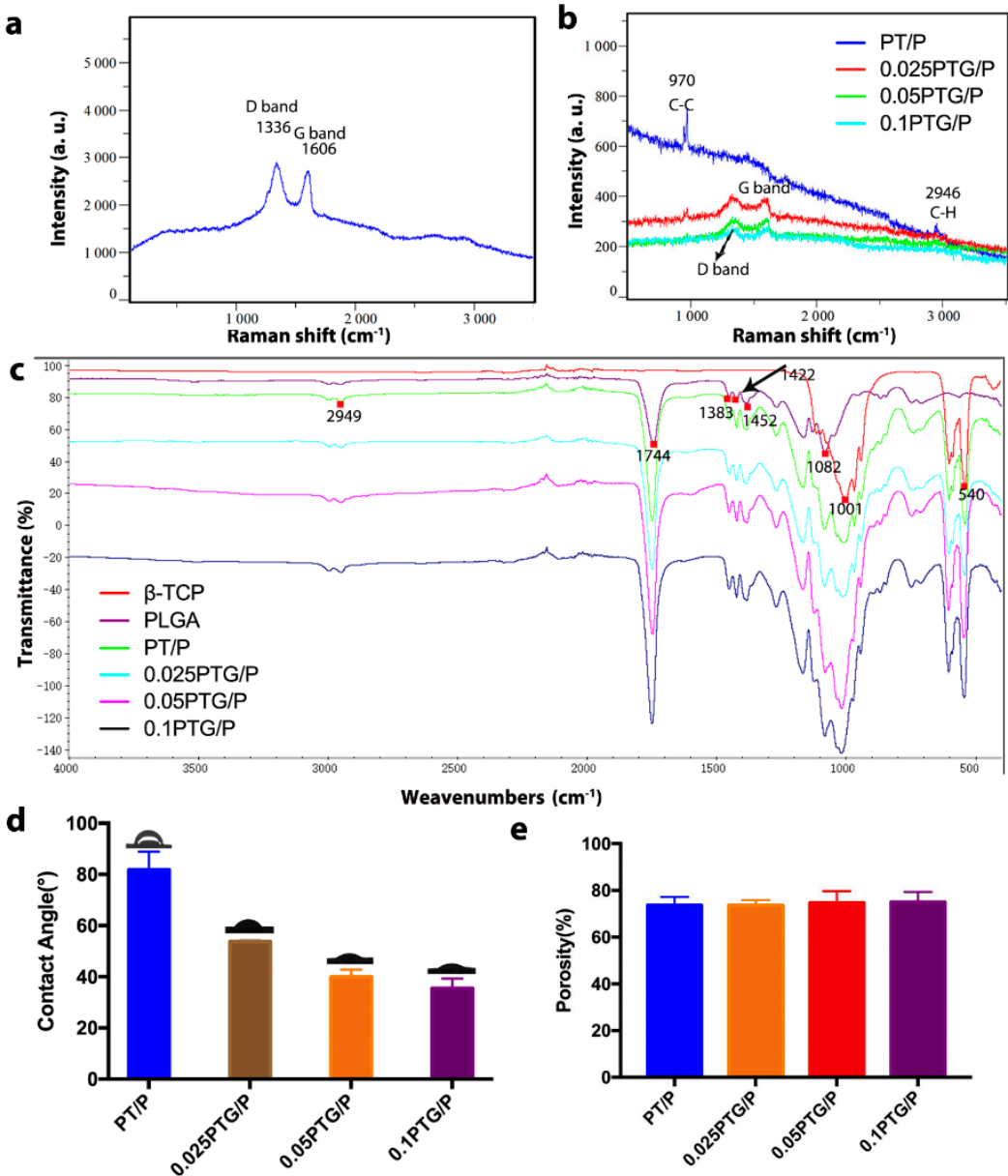

Figure 3. Characterization of surface chemical properties: (a) Raman spectrum of GO; (b) Raman spectra of PT/P, 0.025PTG/P, 0.05PTG/P, and 0.1PTG/P; (c) FTIR-ATR spectra of scaffolds; (d) WCA of PT/P, 0.025PTG/P, 0.05PTG/P, and 0.1PTG/P; (e) Porosity of PT/P, 0.025PTG/P, 0.05PTG/P, and 0.1PTG/P.

\subsection{Scaffold Degradation and In Vitro Peptide Release}

To investigate the effects of GO nanosheets on the degradation behavior of PT/P composite scaffolds, the weight loss and compressive strength were measured. The average compressive strength of PT/P, 0.025PT/P, 0.05PT/P, and 0.1PT/P scaffolds at week 0 was $8.39 \pm 0.87,8.44 \pm 1.25,11.56 \pm 0.749$, and $14.17 \pm 1.63 \mathrm{MPa}$, respectively, suggesting that these scaffolds had enough strength to withstand the external forces during the regeneration process of the non-load-bearing bone tissue. Notably, scaffolds with GO incorporated presented higher compressive strength than that of the PT and PT/P groups. During the degradation test period, the $0.05 \mathrm{PTG} / \mathrm{P}$ and $0.1 \mathrm{PTG} / \mathrm{P}$ groups showed a higher compressive strength compared with the $\mathrm{PT} / \mathrm{P}$ and $0.025 \mathrm{PTG} / \mathrm{P}$ groups. The decrease in compressive strength became significant after week 6 (Figure $4 \mathrm{a}$ ). Figure $4 \mathrm{~b}$ shows that the weight of all scaffolds changed slightly in the first 2 weeks. From 6 weeks to 8 weeks, significant weight changes were obtained for all scaffolds except the 0.1PTG/P scaffolds. Slower weight loss was observed in the 0.05PTG/P and 0.1PTG/P groups. The overall morphology of the scaffolds did not change significantly. However, more pores with bigger size were observed in SEM images (Figure S4). The release of the peptide from the 0.025PTG/P, 0.05PTG/P, and 0.1PTG/P scaffolds was slower than that from the PT/P scaffolds (Figure $4 \mathrm{c}$ ). The peptide release from the $0.05 \mathrm{PTG} / \mathrm{P}$ scaffolds plateaued after 12 days. No significant difference was observed between the 0.025PTG/P and the PT/P groups. The 0.1PTG/P scaffolds had the lowest peptide release rate, in which only $61.82 \pm 0.68 \%$ of the peptide was released within 30 days. 

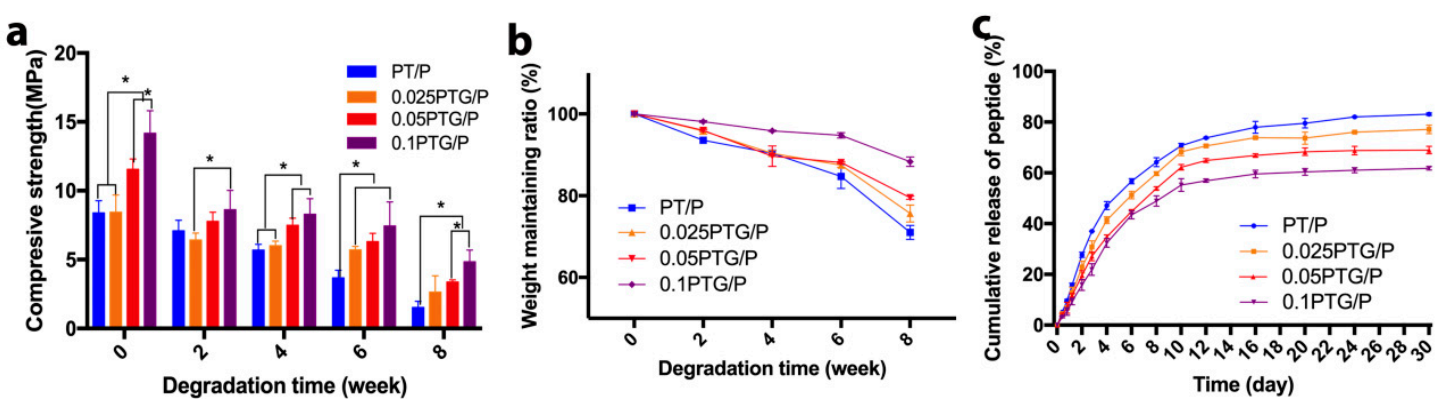

Figure 4. Degradation performance and peptide release of different scaffolds: (a) Compressive strength changes in PT/P, 0.025PTG/P, 0.05PTG/P, and 0.1PTG/P scaffolds during degradation; (b) Weight remaining ratio of $\mathrm{PT} / \mathrm{P}, 0.025 \mathrm{PTG} / \mathrm{P}, 0.05 \mathrm{PTG} / \mathrm{P}$, and 0.1PTG/P scaffolds; (c) Release of BMP-2-like peptide from $\mathrm{PT} / \mathrm{P}, 0.025 \mathrm{PTG} / \mathrm{P}, 0.05 \mathrm{PTG} / \mathrm{P}$, and 0.1PTG/P scaffolds during degradation. ${ }^{*} p<0.05$.

\subsection{In Vitro Biological Performance}

\subsubsection{Cell Viability}

The cytotoxicity of the scaffolds was examined by live (green)/dead (red) assay after culturing the rMSCs on the scaffolds for 3 days. The rMSCs displayed a good initial adhesion among all the groups, and there was no dead cell detected on the scaffolds (Figure 5a). The average live cell ratio on the scaffolds was approximately $97.8 \%$, and no statistical difference in the live cell ratio was found among the different scaffolds (Figure $5 b$ ).
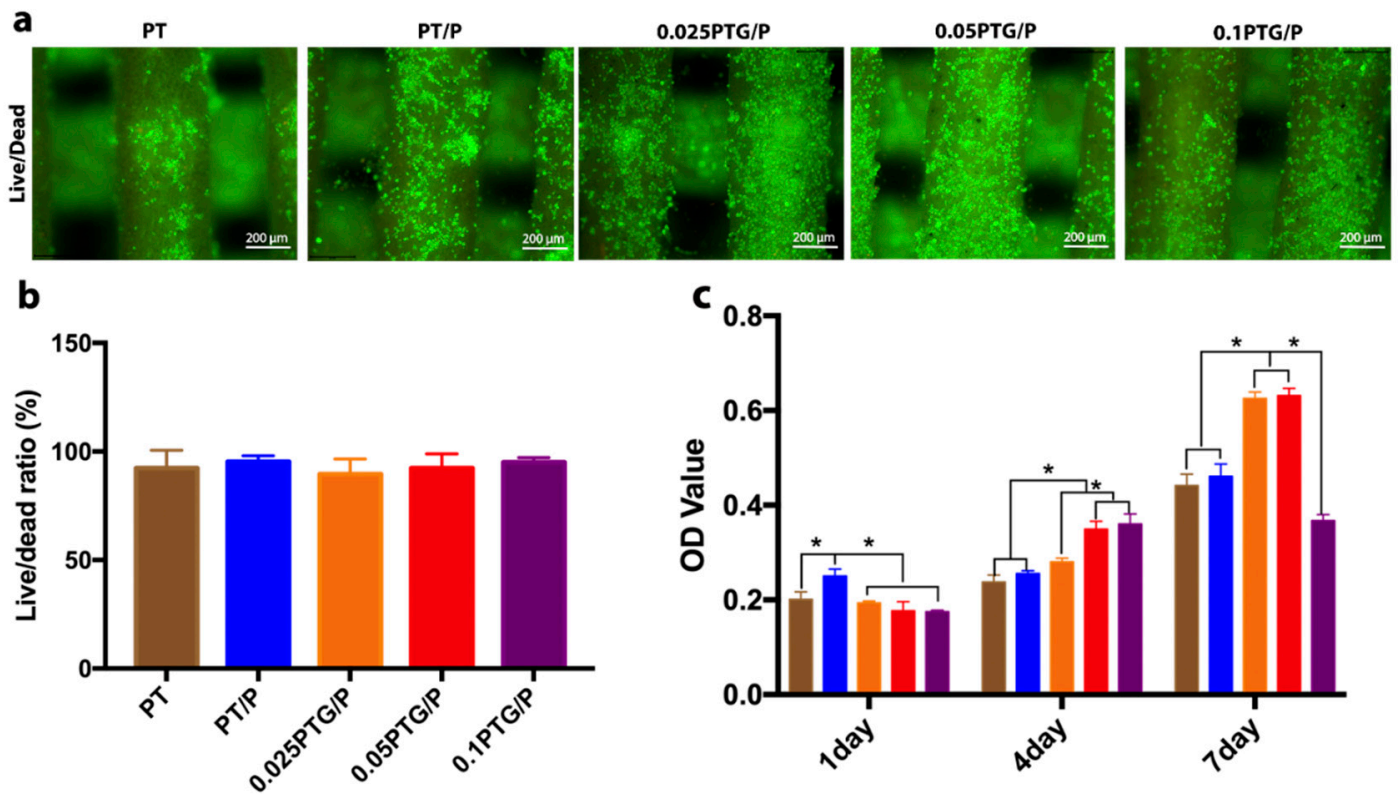

Figure 5. Cell viability and cell proliferation: (a) Fluorescence micrographs representing the live (green) and dead (red) cells of rMSCs cultured on PT, PT/P, 0.025PTG/P, 0.05PTG/P, and 0.1PTG/P scaffolds after being cultured for 1 day; (b) Live cell/dead cell ratio from the live/dead assay; (c) Cell proliferation of rMSCs cultured on PT, PT/P, 0.025PTG/P, 0.05PTG/P, and 0.1PTG/P scaffolds after being cultured for 1 , 4 , and 7 days. ${ }^{*} p<0.05$.

Cell proliferation was examined on days 1, 4, and 7 using the CCK-8 kit assay. The absorbance of rMSCs cultured on all scaffolds showed an increase in the proliferation rate with increasing culture time (Figure $5 \mathrm{c}$ ). The proliferation rate of the PT/P group was observed to be higher than the other groups on the first day, possibly because of the fast release of the peptide. The $0.025 \mathrm{PTG} / \mathrm{P}$ and $0.05 \mathrm{PTG} / \mathrm{P}$ scaffolds showed a significant increase in proliferation rate from day 4 to day 7 , and the increase was 
greater than that of the other groups. The rMSCs on the 0.1PTG/P and PT scaffolds proliferated slower than those in the other groups as measured on day $7(p<0.05)$.

\subsubsection{Cell Adhesion and Morphology}

Figure 6 shows the CLSM images of the cytoskeleton and adhesive plaques of rMSCs cultured on different scaffolds for $24 \mathrm{~h}$. The fluorescence micrographs clearly reveal that rMSCs had successfully attached to the scaffolds and spread well. Evident F-actin filaments were observed in all groups (Figure 6a). Extensive F-actin filaments and more vinculin adhesive plaques were expressed in rMSCs on the 0.025PTG/P, 0.05 PTG/P, and 0.1PTG/P scaffolds compared with those on the PT and PT/P scaffolds, indicating good initial adhesion of rMSCs (Figure $6 \mathrm{~b}, \mathrm{c}$ ). These results suggest that the incorporation of GO into the scaffolds positively influenced the adhesion and maturation of rMSCs.

a

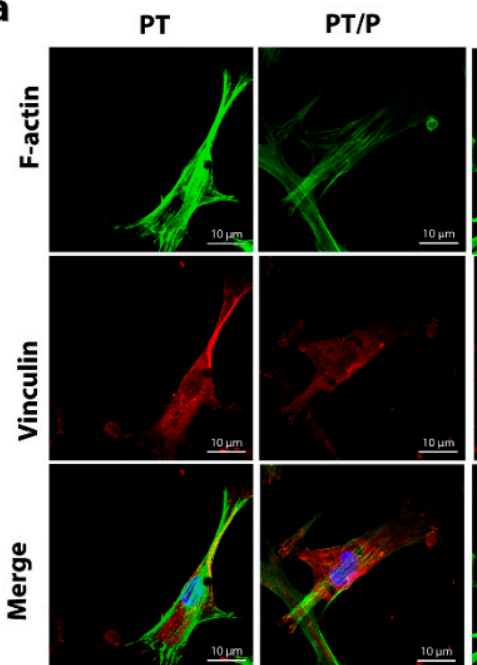

0.025 PTG/P
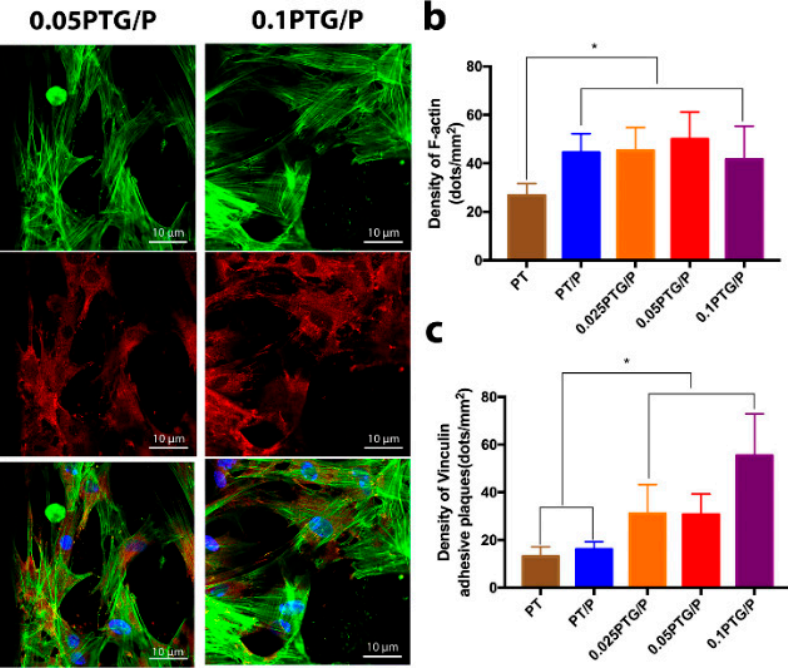

Figure 6. CLSM images of rMSCs on the different scaffolds: (a) CLSM images show the cytoskeleton and adhesive plaques of rMSCs on PT, PT/P, 0.025PTG/P, 0.05PTG/P, and 0.1PTG/P scaffolds, with $\mathrm{F}$-actin stained in green, nuclei stained by DAPI, and vinculin stained in red after cells were cultured on scaffolds for 1 day; (b) Relative fluorescence unit analysis of F-actin in different groups; (c) Relative fluorescence unit analysis of vinculin in different groups. ${ }^{*} p<0.05$.

SEM images show that the morphologies of rMSCs on the 0.025PTG/P, 0.05PTG/P, and 0.1PTG/P scaffolds were plumper than those on the PT scaffolds, exhibiting a typical osteoblast-like morphology. The high magnification images clearly showed the boundary between cells and the scaffolds. The cell membrane was rougher than the surface of the scaffolds (Figure 7). 

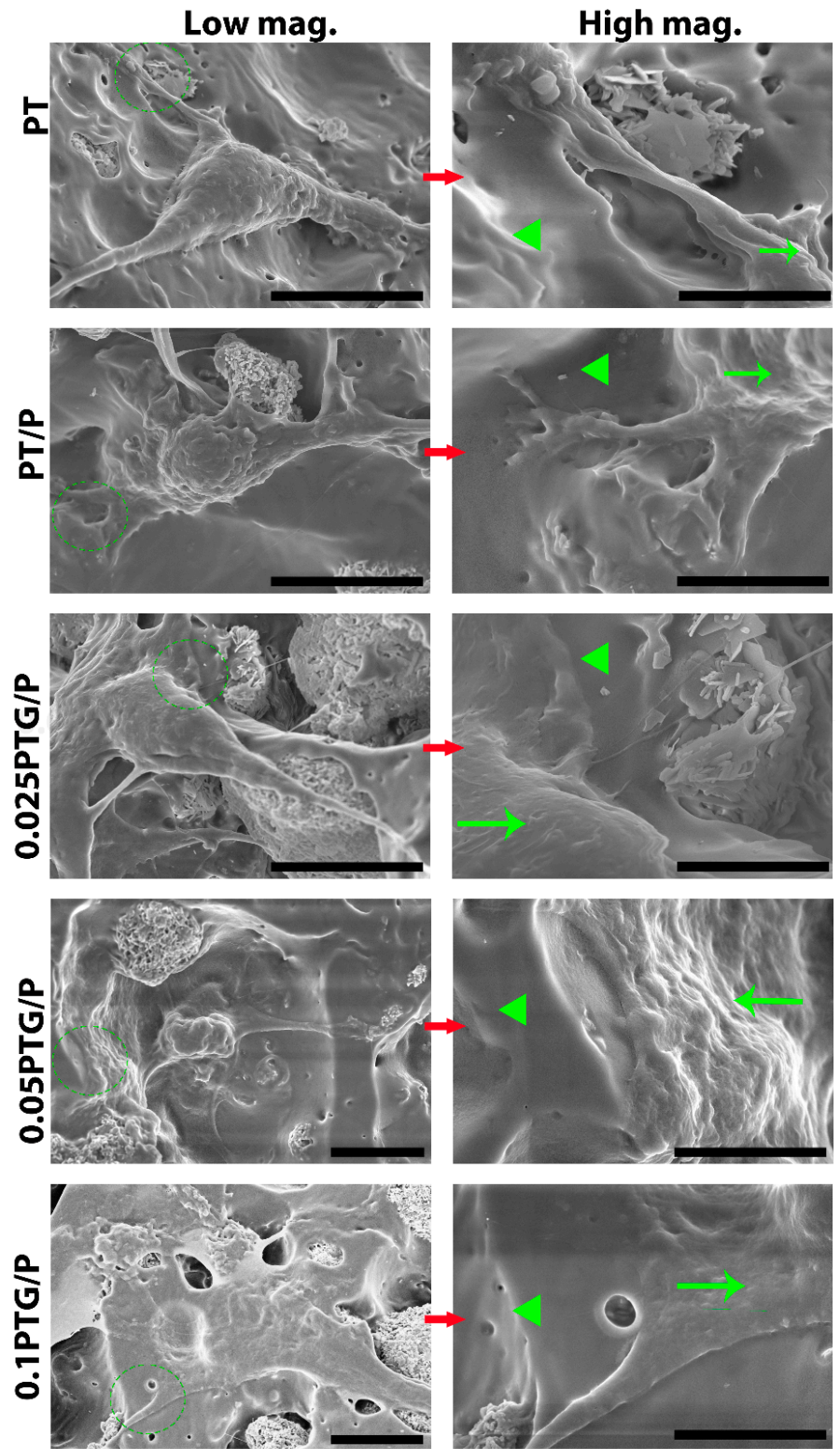

Figure 7. SEM images show the morphology of rMSCs on different scaffolds with low magnification and high magnification of the green circles in the corresponding low magnification images. Notes: green triangles represents the PLGA matrix; the green arrows represent the cell membrane; scale bars of low magnification images are $10 \mu \mathrm{m}$; scale bars of high magnification images are $5 \mu \mathrm{m}$.

\subsection{Osteogenic Differentiation of $r M S C s$}

ALP staining was conducted to study the osteogenic differentiation of rMSCs. Compared with those in the PT and PT/P groups, the rMSCs in the 0.025PTG/P, 0.05PTG/P and 0.1PTG/P groups were larger and darker in color (Figure 8a), suggesting that the addition of GO enhanced the ALP expression of rMSCs; this observation was further confirmed by the ALP activity assay (Figure 8b). The cells cultured on the PT/P scaffolds had higher ALP activity than those in the PT group on day 7. On day 14, the scaffolds containing GO displayed an obvious increase in ALP activity, and the 0.05PTG/P and 0.1 PTG/P groups showed the highest ALP activity among all the groups $(p<0.05)$. ARS staining was used to examine the mineralization of rMSCs after being treated with the conditioned medium for 21 days. Obvious calcium nodules were observed in the peptide-containing groups, whereas no discernible calcium nodule was present in the PT group (Figure 8a). Compared with those of 
the other groups, the calcium nodules deposited in the 0.05PTG/P and 0.1PTG/P groups were larger. Furthermore, no difference between the $0.025 \mathrm{PTG} / \mathrm{P}$ and PT/P groups was found.
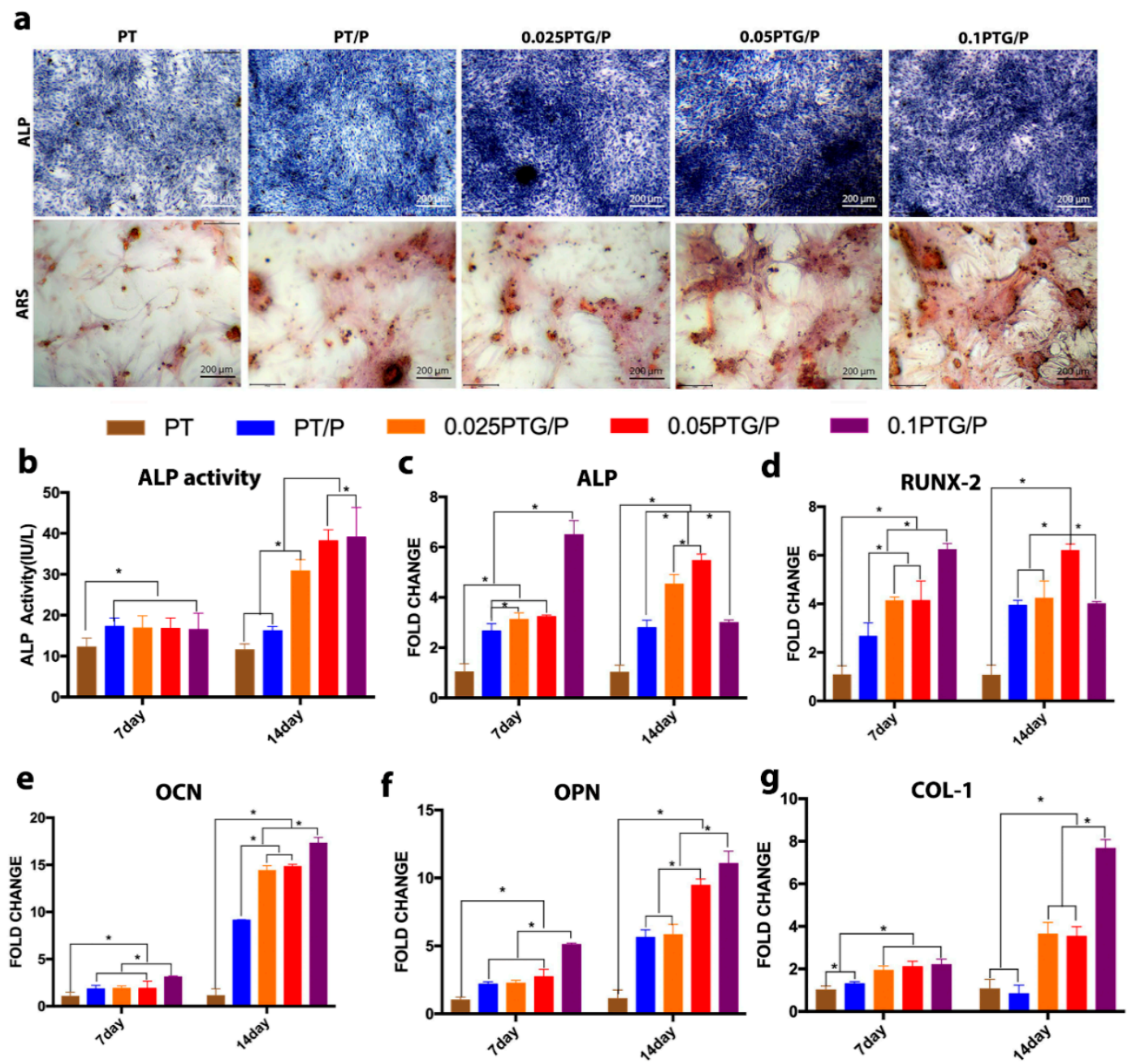

Figure 8. In vitro osteogenic differentiation of rMSCs: (a) ALP staining after 7-day induction and ARS staining after 21-day induction. (b) ALP activity determined by ALP activity assay. Relative gene expression of (c) ALP, (d) RUNX-2, (e) OCN, (f) OPN, and (g) COL-I. * $p<0.05$.

The qPCR results showed the gene expression levels of bone-related genes, including ALP, RUNX-2, OCN, OPN, and COL-I, of rMSCs. For ALP, the 0.1PTG/P group had the highest gene expression level on day 7, but this level had decreased by day 14 (Figure 8c). The ALP expression in the $0.025 \mathrm{PTG} / \mathrm{P}$ and $0.05 \mathrm{PTG} / \mathrm{P}$ groups was significantly upregulated on day 14 , and the levels of expression were higher than those of the other groups $(p<0.05)$. For RUNX-2, the expression was upregulated with increasing GO content on day 7. In comparison, on day 14 , the expression level of the 0.1PTG/P group had significantly decreased $(p<0.05)$, and that of the $0.05 \mathrm{PTG} / \mathrm{P}$ group was the highest. No significant change was observed in the $0.025 \mathrm{PTG} / \mathrm{P}, \mathrm{PT} / \mathrm{P}$, and $\mathrm{PT}$ groups from day 7 to day 14 (Figure 8d). For OCN and OPN, the expression levels of the PT/P, 0.025PTG/P, 0.05PTG/P, and 0.1PTG/P groups were higher than those of the PT group on day 7 . Significant upregulation was observed in the PT/P, 0.025PTG/P, 0.05PTG/P, and 0.1PTG/P groups on day 14 , and a higher expression level in the GO-containing groups was observed compared with that in the PT/P group $(p<0.05)$ (Figure 8e,f). The expression level of COL-I is shown in Figure 8g. The expression level was higher in the $0.025 \mathrm{PTG} / \mathrm{P}, 0.05 \mathrm{PTG} / \mathrm{P}$, and $0.1 \mathrm{PTG} / \mathrm{P}$ groups than in the $\mathrm{PT}$ and $\mathrm{PT} / \mathrm{P}$ groups on day 7 . This trend was maintained until day 14 , at which time the $0.1 \mathrm{PTG} / \mathrm{P}$ group exhibited the highest level $(p<0.05)$. 


\subsection{In Vivo Bone Regeneration Ability}

To further study biological performance, we conducted an in vivo animal test for 12 weeks to confirm the bone regeneration ability of the scaffolds. Critical-sized calvarial defects were successfully created in rats to establish the animal model (Figure 9a). Scaffolds with a diameter of $5 \mathrm{~mm}$ were implanted in the animal models to evaluate in vivo bone regeneration. The 3D reconstructed images are displayed in Figure 9c. At 4 weeks, little bone was formed in the control group, while, for the implant groups, more bone was formed in the scaffolds with peptide compared with the PT group. No significant difference was observed between the PT/P and PTG/P groups at week 4 . When the implantation time was extended to 12 weeks, more bone was observed in the groups with scaffolds than the control group. Notably, there was more bone in the PTG/P group compared with the other groups. Furthermore, the bone volume (BV) and bone surface (BS) were quantitatively analyzed to confirm the bone regeneration ability. The BV results showed that the animals in the PTG/P group formed more bone than those in the other groups (Figure 9d). The BS results showed the same trend as that observed for BV (Figure 9e).
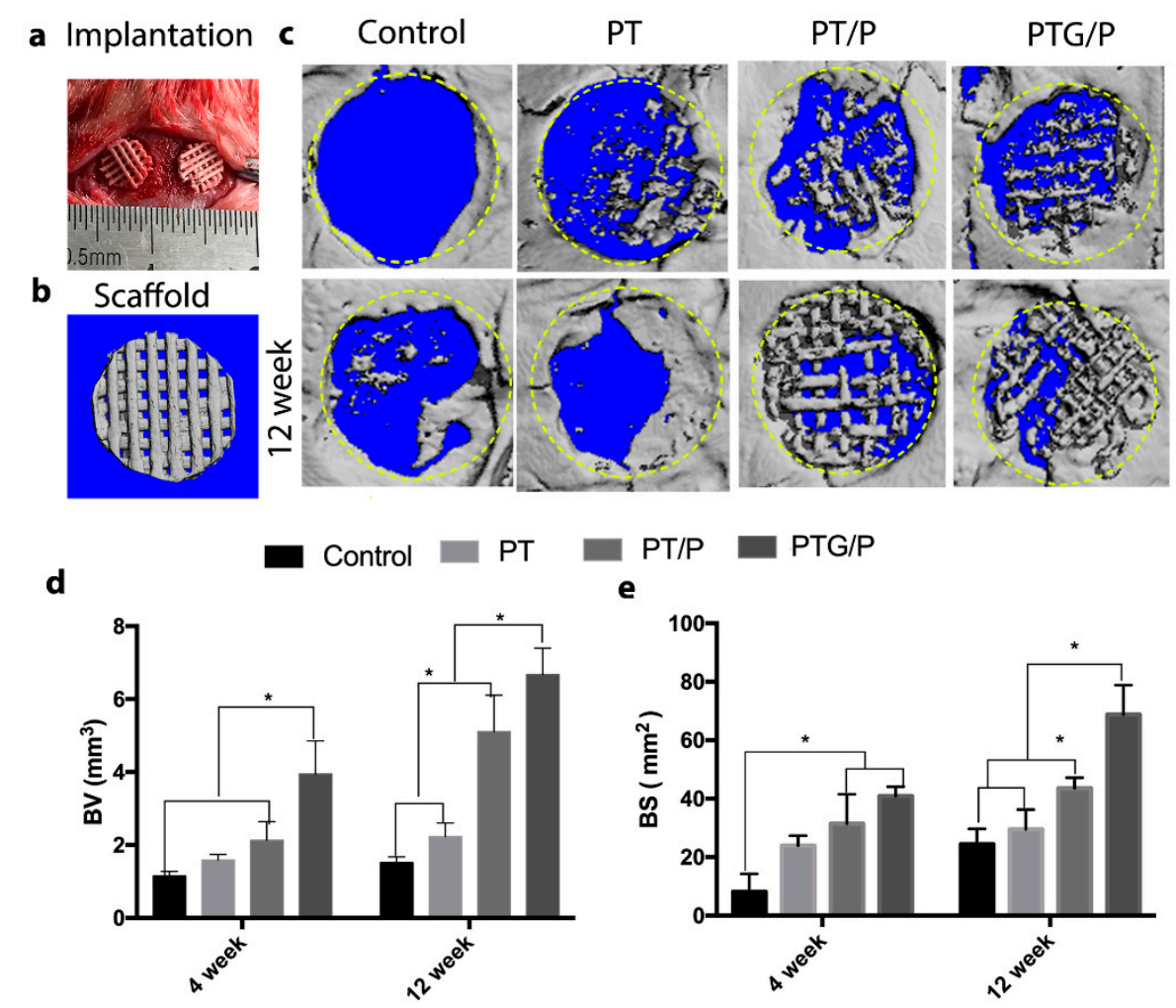

Figure 9. The micro-CT results of the in vivo animal test: (a) Implantation procedure; (b) Micro-CT image of the scaffold; (c) 3D reconstructed images of the control, PT, PT/P, and PTG/P scaffolds after implantation at 4 weeks (top row) and 12 weeks (bottom row); (d) The bone volume (BV) of the newly formed bone in the critical-size defects; (e) The bone surface (BS) of the newly formed bone in the critical-size defects. ${ }^{*} p<0.05$.

We used the fluorescent labeling technique to assess the speed of bone formation. In Figure 10a, there are more red alizarin and green calcein labels in the PT/P and PTG/P groups than there are in the control group; the labels reflect new bone formation at 2 and 4 weeks post-surgery. We also analyzed the mineral apposition rate (MAR), and Figure 10b shows that the MAR was significantly higher in the PTG/P group $(2.94 \pm 0.23 \mu \mathrm{m} /$ day $)$ than the PT/P group $(1.62 \pm 0.38 \mu \mathrm{m} /$ day $)$. Furthermore, toluidine blue staining revealed that there was a line between the host bone and the native bone (white arrow in the figure), and more new bone was formed in the PTG/P group (Figure 10a). In the 
images of Methylene blue acid fuchsin staining, new bone formation (dark pink staining) is evident around the residual PTG/P scaffolds. In the control group, there was a slight amount of new bone formed at the edges of the host bone (pink staining), with more osteoid bone (blue staining) present (Figure 10a). Quantitative analysis of new bone formation (Figure 10c) indicated that there was more new bone formation in the PTG/P group than that in the other groups, confirming that the PTG/P scaffold could significantly promote bone regeneration in vivo. In addition, no abnormalities were detected in pathological sections of major organs (Figure S5).

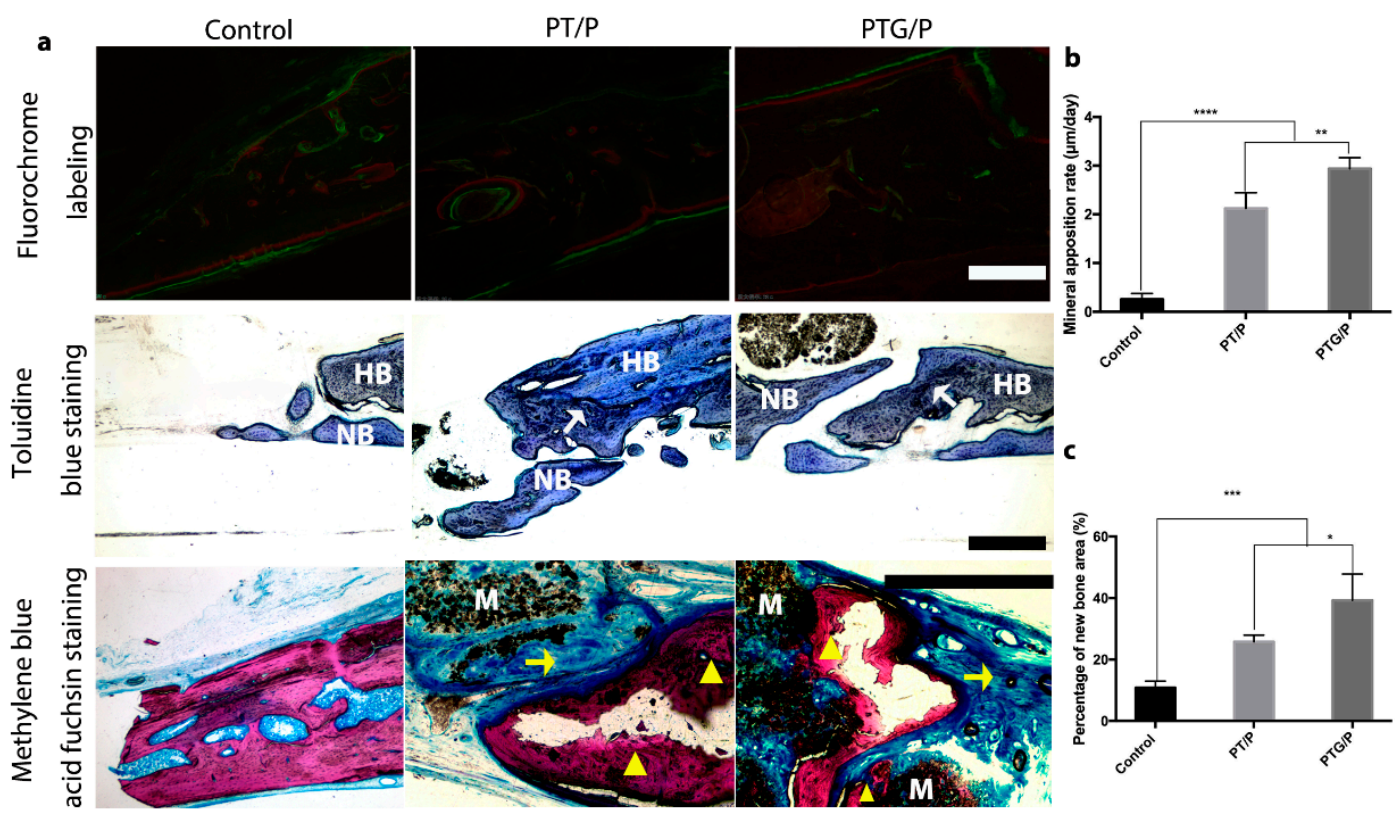

Figure 10. Bone regeneration after 12 weeks: (a) Sequential labeling at 2 weeks (alizarin red S) and 4 weeks (green calcein); Toluidine blue staining of calvarial bone at 12 weeks after surgery. "HB" represents host bone; "NB" represents newly formed bone. There is a line between newly formed bone and the host bone (white arrow); Methylene blue acid fuchsin staining of calvarial bone at 12 weeks after surgery. Notes: yellow triangles indicate the new bone and yellow arrows represent osteoid bone. " $\mathrm{M}$ " represents the residual materials. (b) Mineral apposition rate from 2 weeks to 4 weeks post-surgery; (c) Percentage of new bone area (\%). Scale bars: $250 \mu \mathrm{m} .{ }^{*} p<0.05,{ }^{* *} p<0.01,{ }^{* * *} p<0.001$, $* * * * p<0.0001$.

\section{Discussion}

The primary objective of this study is to produce a biodegradable composite scaffold with significantly improved bone forming ability. This study is the first to realize this objective by the in situ loading of an osteogenic peptide and GO nanosheets into non-sintered scaffolds through advanced cryogenic 3D printing. Compared with scaffolds made by conventional 3D printing techniques, our scaffolds not only have a biomimetic macro/microstructure but also are mechanically similar to human cancellous bone, which is desirable for a bone regeneration substitute. Moreover, our scaffolds could load a significantly higher level of the osteogenic peptide and GO via in situ incorporation without lowering the biological activity of the peptide. GO was also found to further tune the release behavior of the peptide to be more sustained. Such sustained delivery of the osteogenic peptide with both high biological activity and high loading level was expected to significantly improve in vitro osteogenic differentiation and in vivo bone regeneration.

The surface morphology of the scaffolds can influence cell adhesion, proliferation, and even differentiation [22]. Porous scaffolds with a macropore size of 100-500 $\mu \mathrm{m}$ have been shown to facilitate nutrient transport, creeping substitution of bone, and vascular ingrowth [23-25]. In addition, the microstructures on the surface of the scaffolds successfully extended the surface area and improved 
the roughness of the scaffolds, both of which are favorable for initial cell attachment, adhesion, and spreading [26-28]. In our study, the rectangular macropores had a side length of $400 \pm 50 \mu \mathrm{m}$, and the micropores on struts had a diameter of 5-50 $\mu \mathrm{m}$, which are dimensions that meet the standards cited above. Different from other studies, the cryogenic 3D printing method created a hierarchical structure in an environmentally friendly manner by using water droplets in emulsion inks as the pore-forming agent of micropores. The cryogenic environment turns the water droplets into ice particles and reserves them in the scaffold, resulting in a hierarchically porous structure with macro- and microfeatures after lyophilization. Additionally, according to the Raman spectra and FTIR results, the GO nanosheets were successfully incorporated into the scaffolds, and they not only endowed the scaffolds with a specific nanostructure but also enhanced their wettability by introducing $\mathrm{COOH}^{-}$and $\mathrm{OH}^{-}$to the scaffolds' surface.

An ideal scaffold for bone regeneration serves as a template during the bone regeneration process and is replaced by the newly formed bone as it degrades. Good mechanical performance is of great importance because it allows the scaffolds to maintain their space, withstand external forces, and avoid stress shielding. Volatilization of the organic solvent during the fabrication process would cause deformation of the scaffolds and thus reduce the mechanical strength. The low temperature of cryogenic 3D printing used in this study prevented the deformation of the scaffolds, endowing them with high mechanical strength. Besides this, we found that the incorporation of GO significantly improved the compressive strength of the PTG/P scaffolds as a result of its excellent physical-chemical properties [29,30]. Notably, the compressive strength of the 0.025PTG/P, 0.05PTG/P, and 0.1PTG/P scaffolds was within the range of that of trabecular bone (2-20 MPa) [31] after degrading for 8 weeks; thus, the scaffold conferred temporary support and guaranteed its function during the mineralization process [29-32]. The weight loss was also influenced by the incorporation of GO. A slower weight change of the PTG/P composite scaffolds compared with that of the PT/P scaffolds could imply that the interactions between GO nanosheets and the PT/P matrix stabilized the matrix, thus reducing the degradation rate [29].

Cryogenic 3D printing resulted in the in situ loading of the peptide and GO, allowing the peptide to diffuse into the scaffolds and be released from a deeper layer of the scaffold matrix to the outer environment through the pores formed by scaffold degradation, and this could slow the sustained release rate of the peptide in the scaffolds. The functional groups, such as epoxide, carboxyl, and hydroxyl groups, that are present on the basal plane and edges of GO can interact with peptides through covalent, electrostatic, and hydrogen bonding [33], further explaining the slower peptide release in the PTG/P scaffolds compared with that of the PT/P scaffolds. These results indicate that our PTG/P scaffolds can serve as an effective vehicle system for sustained peptide delivery, which is conducive to the favorable biological performance of the scaffolds.

Bone regeneration materials should stimulate favorable cellular responses [34]. The macro/micro/nanosurface, as well as the enhanced wettability of our scaffolds, significantly improved cell attachment. In addition, the interconnective pores in the scaffolds would facilitate nutrient transportation and metabolic waste removal, thus making it a friendly microenvironment in which rMSCs can proliferate and infiltrate. The cytotoxicity of GO nanosheets has been reported to be associated with their size, concentration, and interaction time; that is, GO with a larger size and a higher local concentration will induce a decrease in cell viability, while GO with a lower concentration and a smaller size can positively affect cellular behaviors [35]. Cryogenic 3D printing formed a macro/micro/nanostructure in a green process and retained the bioactivity as well as the original properties of the raw materials, which can minimize the cytotoxicity of the scaffolds and release the biomolecules/drugs in a long-term process. According to the degradation results, further controlling GO enabled the PTG/P scaffolds to release the peptide more sustainably, which was favorable for the growth and osteogenic differentiation of rMSCs. Therefore, the sustained release of a bioactive factor could explain the increase in cell proliferation on the 0.025PTG/P and 0.05PTG/P scaffolds on day 4 and day 7 . The slower proliferation rate for the $0.1 \mathrm{PTG} / \mathrm{P}$ group observed on day 7 compared 
with the $0.025 \mathrm{PTG} / \mathrm{P}$ and $0.05 \mathrm{PTG} / \mathrm{P}$ groups may be due to the high concentration of GO generating ROS, which compromises the proliferation rate. Vinculin and F-actin are mainly expressed during the formation of focal adhesion and the aggregation assembly of membrane cytoskeletons, respectively [36]. F-actin and vinculin could reflect the cytoskeleton and adhesion plaques of cells. The low F-actin and vinculin density of PT group was due to the contracted cell morphology and the low cell viability according to the CCK-8 results. The high F-actin density of PT/P, 0.025PTG/P, 0.05PTG/P and 0.1PTG/P groups was due to the rapid peptide release in the initial stage which was favorable for the cell growth. The vinculin density was similar for PT and PT/P group. The higher vinculin density of 0.025PTG/P, 0.05PTG/P and 0.1PTG/P groups compared to PT and PT/P group was because that the oxygen-containing group and topographical features of GO contained scaffolds could greatly enhance the initial cell adhesion $[37,38]$. In addition, the higher wettability of these GO contained scaffolds could also explain the higher vinculin density of rMSCs on them [39]. Moreover, GO was reported to adsorb serum protein and pro-concentrate osteogenic inducers, such as dexamethasone, $\beta$-glycerophosphate, and ascorbic acid, through the interaction between the $\pi-\pi$ electron cloud in GO and the aromatic rings in the biomolecules, which is also beneficial for osteogenic differentiation [34-40]. Therefore, the increase in ALP activity level in the $0.05 \mathrm{PTG} / \mathrm{P}$ and $0.1 \mathrm{PTG} / \mathrm{P}$ groups on day 14 may be the result of the sustained release of the peptide and the intrinsic properties of GO. In addition, the improved cell mineralization also suggests the excellent osteostimulatory activity of the PTG/P scaffolds. The osteogenic differentiation ability was examined at the gene expression level. ALP and RUNX-2 are expressed at the early stage of bone formation. The former is related to active bone formation, whereas the latter is an important transcription factor for osteogenic differentiation, and it regulates the downstream expression of other phenotypic markers [41-43]. In comparison, OCN and OPN are expressed at the late stage of osteogenic differentiation and are associated with the formation of mineralized bone-like nodules [44]. In this study, the notable upregulated expression of the ALP and RUNX-2 genes in the 0.1PTG/P group could be attributed to the expression of these two genes at the early stage of bone formation, and the high GO concentration could accelerate their expression and cell maturation at an early stage [18]. In accordance with the cell mineralization results, the sustained release of the peptide also significantly increased the expression level of OCN, OPN, and COL-1 measured on day 14. In our in vivo study, the scaffolds containing GO showed better bone formation ability than the PT/P group after 12 weeks; this finding could be attributed to the ability of the scaffolds containing GO to release the peptide in a more sustained manner than the PT/P scaffolds. The sustained release of the peptide constantly stimulates bone regeneration in vivo; hence, more bone was formed around the PTG/P scaffolds. In summary, the sustained release of the peptide and the incorporation of GO nanosheets into the scaffolds significantly upregulated the osteogenic differentiation of rMSCs and could achieve long-term bone regeneration.

\section{Conclusions}

In this study, PTG/P composite scaffolds with in situ loading of GO@peptide were successfully produced using cryogenic 3D printing. The scaffolds had a hierarchically porous structure with controlled macro- and micropores. The compressive strength of the scaffolds improved with increasing GO content, which also enhanced their surface wettability. The sustained release of the peptide in the PTG/P scaffolds due to the in situ loading strategy and the high adsorption ability of GO nanosheets was beneficial for bone growth and promoted the proliferation and adhesion of rMSCs. Additionally, the incorporation of GO nanosheets into the scaffolds significantly enhanced the osteogenic differentiation of rMSCs. Finally, the PTG/P scaffolds significantly improved bone regeneration in vivo. These results indicate that the cryogenic 3D-printed PTG/P scaffolds are a promising platform for inducing bone regeneration.

Supplementary Materials: The following are available online at http://www.mdpi.com/1420-3049/24/9/1669/s1. 
Author Contributions: Validation, investigation, data curation, writing-original draft preparation, Y.Z. (Yidi Zhang); conceptualization, validation, writing-original draft preparation, writing-review and editing, C.W.; investigation, writing- review and editing, L.F.; formal analysis, investigation, writing-review and editing, S.Y.; validation, writing-review and editing, M.W.; conceptualization, supervision, Y.Z. (Yanmin Zhou).

Funding: This research was funded by [National Natural Science Foundation of China] grant number [51627805]; [Department of Finance of Jilin Province] grant number [QT10646]; [Department of Science and Technology of Jilin Province] grant number [20160101138JC]; [Natural Science Foundation of Guangdong Province] grant number [2018A0303130019]; [Department of Education of Guangdong Province] grant number [2016KQNCX168]; and [Dongguan University of Technology] grant number [KCYCXPT2016003].

Acknowledgments: The authors express their appreciation for the financial support of the National Major Research and Development Projects of Scientific Instruments (51627805), Science and Technology Development Plan Project of Jilin Province (20160101138JC), The Health Projects of Jilin Province (QT10646), Dongguan University of Technology High-Level Talents (Innovation Team) Research Project (KCYCXPT2016003), Youth Innovative Talent Project (2016KQNCX168) from the Department of Education of Guangdong Province, China and Natural Science Foundation Project of Guangdong Province, China (2018A0303130019).

Conflicts of Interest: There are no conflicts of interest to declare.

\section{References}

1. Dimitriou, R.; Jones, E.; Mcgonagle, D.; Glannoudis, P.V. Bone regeneration: Current concepts and future directions. BMC Med. 2011, 9, 66. [CrossRef] [PubMed]

2. Finkemeier, C.G. Bone-Grafting and Bone-Graft Substitutes. J. Bone Joint. Surg. Am. 2002, 84, 454-464. [CrossRef]

3. Qi, Y.; Tai, Z.; Sun, D.F.; Chen, J.; Ma, H.; Yan, X.; Liu, B.; Xue, Q. Fabrication and characterization of poly(vinyl alcohol)/graphene oxide nanofibrous biocomposite scaffolds. J. Appl. Polym. Sci. 2013, 127, 1885-1894. [CrossRef]

4. Kankala, R.K.; Xu, X.; Liu, C.; Chen, A.; Wang, S. 3D-Printing of Microfibrous Porous Scaffolds Based on Hybrid Approaches for Bone Tissue Engineering. Polymers 2018, 10, 807. [CrossRef] [PubMed]

5. Carreira, A.C.; Lojudice, F.; Halcsik, H.E.; Navarro, R.D.; Sogayar, M.C.; Granjeiro, J.M. Bone morphogenetic proteins: Facts, challenges, and future perspectives. J. Dent. Res. 2014, 93, 335-345. [CrossRef]

6. Cui, W.; Sun, G.; Qu, Y.; Xiong, Y.; Sun, T.; Ji, Y.; Yang, L.; Shao, Z.; Ma, J.; Zhang, J.S.; et al. Repair of rat calvarial defects using Si-doped hydroxyapatite scaffolds loaded with a bone morphogenetic protein-2-related peptide. J. Orthop. Res. 2016, 34, 1874-1882. [CrossRef]

7. Bilem, L.; Plawinski, L.; Chevallier, P.; Ayela, C.; Sone, E.D.; Laroche, G.; Durrieu, M.C. The spatial patterning of RGD and BMP-2 mimetic peptides at the subcellular scale modulates human mesenchymal stem cells osteogenesis. J. Biomed. Mater. Res. A 2017, 106, 959-970. [CrossRef] [PubMed]

8. Aghdasi, B.; Montgomery, S.R.; Daubs, M.D.; Wang, J.C. A review of demineralized bone matrices for spinal fusion: The evidence for efficacy. Surgeon 2013, 11, 39-48. [CrossRef]

9. Liao, J.; Wu, S.; Li, K.; Fan, Y.; Dunne, N.; Li, X. Peptide-modified bone repair materials: Factors influencing osteogenic activity. J. Biomed. Mater. Res. A 2019. [CrossRef]

10. Xie, C.; Sun, H.; Wang, K.; Zheng, W.; Lu, X.; Ren, F. Graphene oxide nanolayers as nanoparticle anchors on biomaterial surfaces with nanostructures and charge balance for bone regeneration. J. Biomed. Mater. Res. A 2017, 105, 1311-1323. [CrossRef]

11. Norahan, M.H.; Amroon, M.; Ghahremanzadeh, R.; Mahmoodi, M.; Baheiraei, N. Electroactive graphene oxide-incorporated collagen assisting vascularization for cardiac tissue engineering. J. Biomed. Mater. Res. A 2019, 107, 204-219. [CrossRef]

12. Valencia, C.; Valencia, C.H.; Zuluaga, F.; Valencia, M.E.; Mina, J.H.; Grande-Tovar, C.D. Synthesis and Application of Scaffolds of Chitosan-Graphene Oxide by the Freeze-Drying Method for Tissue Regeneration. Molecules 2018, 23, 2651. [CrossRef] [PubMed]

13. Liu, Z.; Robinson, J.T.; Sun, X.; Dai, H. PEGylated nanographene oxide for delivery of water-insoluble cancer drugs. J. Am. Chem. Soc. 2008, 130, 10876-10877. [CrossRef] [PubMed]

14. La, W.G.; Jin, M.; Park, S.; Yoon, H.H.; Jeong, G.J.; Bhang, S.H.; Park, H.; Char, K.; Kim, B.S. Delivery of bone morphogenetic protein-2 and substance $\mathrm{P}$ using graphene oxide for bone regeneration. Int. J. Nanomed. 2014, 9, 107-116. [PubMed] 
15. Zhang, W.; Yang, G.; Wang, X.; Jiang, L.; Jiang, F.; Li, G.; Zhang, Z.; Jiang, X. Magnetically Controlled Growth-Factor-Immobilized Multilayer Cell Sheets for Complex Tissue Regeneration. Adv. Mater. 2017, 29, 1703795. [CrossRef]

16. Mohammadrezaei, D.; Golzar, H.; Rezai, R.M.; Omidi, M.; Rashedi, H.; Yazdian, F.; Khojasteh, A.; Tayebi, L. In vitro effect of graphene structures as an osteoinductive factor in bone tissue engineering: A systematic review. J. Biomed. Mater. Res. A 2018, 106, 2284-2343. [CrossRef]

17. Luo, Y.; Shen, H.; Fang, Y.; Cao, Y.; Huang, J.; Zhang, M.; Dai, J.; Shi, X.; Zhang, Z. Enhanced Proliferation and Osteogenic Differentiation of Mesenchymal Stem Cells onGrapheneOxideIncorporatedElectrospunPoly(lactic-co-glycolic acid) Nanofibrous Mats. ACS Appl. Mater. Interface 2015, 7, 6331-6339. [CrossRef] [PubMed]

18. Song, J.; Gao, H.; Zhu, G.; Cao, X.; Shi, X.; Wang, Y. The preparation and characterization of polycaprolactone/graphene oxide biocomposite nanofiber scaffolds and their application for directing cell behaviors. Carbon 2015, 95, 1039-1050. [CrossRef]

19. Liu, X.; Shen, H.; Song, S.; Chen, W.; Zhang, Z. Accelerated Biomineralization of Graphene Oxide-Incorporated Cellulose Acetate Nanofibrous Scaffolds for Mesenchymal Stem Cell Osteogenesis. Colloids Surf. B Biointerfaces 2017, 159, 251-258. [CrossRef]

20. Wang, C.; Zhao, Q.; Wang, M. Cryogenic 3D printing for producing hierarchical porous and rhBMP-2-loaded Ca-P/PLLA nanocomposite scaffolds for bone tissue engineering. Biofabrication 2017, 9, 025031. [CrossRef] [PubMed]

21. Meng, X.; Wang, X.; Guo, Y.; Ma, S.; Luo, W.; Xiang, X.; Zhao, J.; Zhou, Y. Biocompatibility evaluation of a newly developed Ti-Nb-Zr-Ta-Si alloy implant. J. Biomater. Tissue. Eng. 2016, 6, 861-869. [CrossRef]

22. Smith, L.E.; Bryant, C.; Krasowska, M.; Cowin, A.J.; Whittle, J.D.; MacNeil, S.; Short, R.D. Haptotatic plasma polymerized surfaces for rapid tissue regeneration and wound healing. ACS Appl. Mater. Interfaces 2016, 8, 32675-32687. [CrossRef] [PubMed]

23. Karageorgiou, V.; Kaplan, D. Porosity of 3D biomaterial scaffolds and osteogenesis. Biomaterials 2005, 26, 5474-5491. [CrossRef] [PubMed]

24. Huri, P.Y.; Ozilgen, B.A.; Hutton, D.L.; Grayson, W.L. Scaffold pore size modulates in vitro osteogenesis of human adipose-derived stem/stromal cells. Biomed. Mater. 2014, 9, 045003. [CrossRef]

25. Sicchieri, L.G.; Crippa, G.E.; Oliveira, P.T.; Beloti, M.M.; Rosa, A.L. Pore size regulates cell and tissue interactions with PLGA-CaP scaffolds used for bone engineering. J. Tissue. Eng. Regen. Med. 2012, 6, 155-162. [CrossRef]

26. Pei, X.; Ma, L.; Zhang, B.; Sun, J.; Sun, Y.; Fan, Y.; Gou, Z.; Zhou, C.; Zhang, X. Creating hierarchical porosity hydroxyapatite scaffold with osteoinduction by three-dimensional printing and microwave sintering. Biofabrication 2017, 9, 045008. [CrossRef] [PubMed]

27. Chen, B.; Kankala, R.K.; Chen, A.; Yang, D.; Chen, X.; Jiang, N.; Zhu, K.; Wang, S. Investigation of silk fibroin nanoparticle-decorated poly(l-lactic acid) composite scaffolds for osteoblast growth and differentiation. Int. J. Nanomed. 2017, 12, 1877-1890. [CrossRef]

28. Kankala, R.K.; Zhu, K.; Li, J.; Wang, C.; Wang, S.; Chen, A. Fabrication of arbitrary 3D components in cardiac surgery: From macro-, micro- to nanoscale. Biofabrication 2017, 9, 032002. [CrossRef]

29. Natarajan, J.; Madras, G.; Chatterjee, K. Development of Graphene Oxide-/Galactitol Polyester-Based Biodegradable Composites for Biomedical Applications. ACS Omega 2017, 2, 5545-5556. [CrossRef]

30. Ruan, J.; Wang, X.; Zhang, Y.; Wang, Z.; Xie, Q.; Zhang, D.; Huang, Y.; Zhou, H.; Bi, X.; Xiao, C.J. Enhanced Physiochemicaland Mechanical Performance of Chitosan-grafted Graphene Oxide for Superior Osteoinductivity. Adv. Funct. Mater. 2016, 26, 1085-1097. [CrossRef]

31. Bose, S.; Roy, M.; Bandyopadhyay, A. Rencent advances in bone tissue engineering scaffolds. Trends Biotechnol. 2012, 30, 546-554. [CrossRef] [PubMed]

32. Bi, L.; Cheng, W.; Fan, H.; Pei, G. Reconstruction of goat tibial defects using an injectable tricalcium phosphate/chitosan in combination with autologous platelet-rich plasma. Biomaterials 2010, 31, 3201-3211. [CrossRef]

33. Lee, W.C.; Lim, C.H.X.; Shi, H.; Tang, L.A.L.; Wang, Y.; Lim, C.T.; Loh, K.P. Origin of Enhanced Stem Cell Growth and Differentiation on Graphene and Graphene Oxide. ACS Nano 2011, 5, 7334-7341. [CrossRef] 
34. Khajuria, D.K.; Kumar, V.B.; Gigi, D.; Gedanken, A.; Karasik, D. Accelerated bone regeneration by nitrogen-doped carbon dots functionalized with hydroxyapatite nanoparticles. ACS Appl. Mater. Interfaces 2018, 10, 19373-19385. [CrossRef]

35. Akhavan, O. Size-dependent genotoxicity of graphene nanoplatelets in human stem cells. Biomaterials 2012, 33, 8017-8025. [CrossRef]

36. Wang, J.; Yang, M.; Zhu, Y.; Wang, L.; Tomsia, A.P.; Mao, C. Phage Nanofibers Induce Vascularized Osteogenesis in 3D Printed Bone Scaffolds. Adv. Mater. 2014, 26, 4961-4966. [CrossRef] [PubMed]

37. Vlček, J.; Lapčík, L.; Havrdová, M.; Polakova, K.; Lapcikova, B.; Opletal, T.; Froning, J.P.; Otyepka, M. Flow induced HeLa cell detachment kinetics show that oxygen-containing functional groups in graphene oxide are potent cell adhesion enhancers. Nanoscale 2019, 11, 3222-3228. [CrossRef] [PubMed]

38. Marrella, A.; Giannoni, P.; Pulsoni, I.; Quarto, R.; Raiteri, R.; Scaglilione, S. Topographical Features of Graphene-Oxide-Functionalized Substrates Modulate Cancer and Healthy Cell Adhesion Based on the Cell Tissue of Origin. ACS Appl. Mater. Interfaces 2018, 10, 41978-41985. [CrossRef]

39. Pulyala, P.; Singh, A.; Dias-Netipanyj, M.F.; Cigi, S.C.; Santos, L.S.; Soares, P.; Gopal, V.; Suganthan, V.; Manivasagam, G.; Popat, K.C. In-vitro cell adhesion and proliferation of adipose derived stem cell on hydroxyapatite composite surfaces. Mater Sci. Eng. C Mater Biol. Appl. 2017, 75, 1305-1316. [CrossRef]

40. Shuai, Y.; Mao, C.; Yang, M. Protein Nanofibril Assemblies Templated by Graphene Oxide Nanosheets Accelerate Early Cell Adhesion and Induce Osteogenic Differentiation of Human Mesenchymal Stem Cells. ACS Appl. Mater. Interfaces 2018, 10, 31988-31997. [CrossRef] [PubMed]

41. Mizuno, M.; Kuboki, Y. Osteoblast-Related Gene Expression of Bone Marrow Cells during the Osteoblastic Differentiation Induced by Type I Collagen. J. Biochem. 2001, 129, 133-138. [CrossRef]

42. Gaur, T.; Lengner, C.J.; Hoyhannisyan, H.; Bhat, R.A.; Bodine, P.V.; Komm, B.S.; Javed, A.; Wijnen van, A.J.; Stein, J.L.; Stein, G.S.; et al. Canonical WNT Signaling Promotes Osteogenesis by Directly Stimulating Runx2 Gene Expression. J. Biol. Chem. 2005, 280, 33132-33140. [CrossRef]

43. Satija, N.K.; Gurudutta, G.U.; Sharma, S.; Afrin, F.; Gupta, P.; Verma, Y.K.; Singh, V.K.; Tripathi, R.P. Mesenchymal stem cells: Molecular targets for tissue engineering. Stem Cells Dev. 2007, 16, 7-23. [CrossRef]

44. Frank, O.; Heim, M.; Jakob, M.; Barbero, A.; Schäfer, D.; Bendik, I.; Dick, W.; Heberer, M.; Martin, I. Real-time quantitative RT-PCR analysis of human bone marrow stromal cells during osteogenic differentiation in vitro. J. Cell Biochem. 2002, 85, 737-746. [CrossRef]

Sample Availability: Samples of the compounds are available from the authors.

(C) 2019 by the authors. Licensee MDPI, Basel, Switzerland. This article is an open access article distributed under the terms and conditions of the Creative Commons Attribution (CC BY) license (http://creativecommons.org/licenses/by/4.0/). 